\title{
Percutaneous Treatment of the Spinal Metastases
}

\author{
A. Zachos*, P. Tranquilli Leali and C. Doria \\ Orthopaedic Department, University of Sassari, Italy
}

\begin{abstract}
Background: The spinal column is the most frequent site of bone metastases, and between $30 \%$ and $70 \%$ of patients with cancer will have evidence of spinal metastasis at autopsy [1,2]. The majority of metastasis occurs in the thoracic spine $(70 \%)$ followed by the lumbar $(20 \%)$ and cervical region $(10 \%)$, [2-4]. The surgical treatment of the vertebral metastases remains a real challenge in spine surgeons. Recent advancements in surgical techniques allow a less aggressive approach of the patient with better results in terms of decreasing pain, improvement of the quality of life. We must avoid the overtreatment of terminally ill patients; some patients may survive for several years and benefit from surgery.
\end{abstract}

Materials and methods: The surgical techniques that we used from August 2006 to October 2011 were the coablation (Figures 2a,2b) associated with vertebroplasty (Figures 3a,3b) and percutaneous osteosynthesis (Figures 4-6). Very important were the operating room set up and the surgical technique. In our clinic, in the last 5 years, were treated 115 patients. With vertebroplasty (Figures 3a,3b) and ablation (Figures 2a,2b) 76 patients (94 vertebrae). We used the percutaneous osteosynthesis (Figures 4-6) in 39 patients aged between 42 and 88 years (mean 65 years). of pain.

Results: In both types of treatment, the postoperative elapsed were regular with early mobilization and regression

Conclusion: The diagnosis and treatment of spinal metastases require multidisciplinary review. The optimal treatment depends from a balance between the morbidity of the surgical procedure, the estimated survival time, and the overall quality of life. We believe that these minimally invasive techniques are certainly a viable alternative to "open" traditional spine surgery and can help in order to reduce the pain and to restore the stability.

\section{Background}

The spinal column is the most frequent site of bone metastases and between $30 \%$ and $70 \%$ of patients with cancer will have evidence of spinal metastasis at autopsy $[1,2]$. The majority of metastasis occurs in the thoracic spine (70\%) followed by the lumbar (20\%) and cervical region (10\%), [2-4]. The surgical treatment of the vertebral metastases remains a real challenge in spine surgeons. Recent advancements in surgical techniques allow a less aggressive approach of the patient with better results in terms of decreasing pain, improvement of the quality of life. Treatment must be individually tailored for each patient in consideration of multiple factors including bony stability, the compression of neural structures, tumor radio sensitivity, pain, and, not least, the patient's overall prognosis. There are minimally invasive surgical procedures may provide immediate pain relief and improve fracture-related spinal deformity.

\section{Epidemiology}

The increase in survival in many types of cancer has increased the incidence of symptomatic spinal metastases. The spinal column is the most frequent site of bone metastases, and between $30 \%$ and $70 \%$ of patients with cancer will have evidence of spinal metastasis at autopsy $[1,2]$. The majority of metastasis occurs in the thoracic spine (70\%) followed by the lumbar (20\%) and cervical region (10\%), [3-5]. The thoracic spine is most commonly involved in metastatic disease, possibly because it contains the greatest volume of bone marrow for receiving metastatic deposits [6]. The vertebral column is the third site most affected after lungs and liver [7]. The most common primary malignancy is prostate cancer for men, followed by lung and colon cancer. For women the first cause for vertebral metastases is the breast cancer, followed by lung and colon cancer. Vertebral metastases occur in all age groups, with the highest incidence between age 40 and 65 years [8].

There are two types of treatment, conservative and surgical:

Conservative and pharmacological treatment of the spinal metastases: Include hormonal therapy, chemotherapy (antitumor drugs and drugs that prevent the effects of tumor), analgesic medication and radiation therapy. Chemotherapy can be divided into antitumor drugs and drugs that prevent or ameliorate the effects of tumor. Antitumor chemotherapy currently plays a relatively limited role in the treatment of spinal metastases. Radiation therapy remains the mainstay of therapy for metastatic spinal tumor is well known that radiation

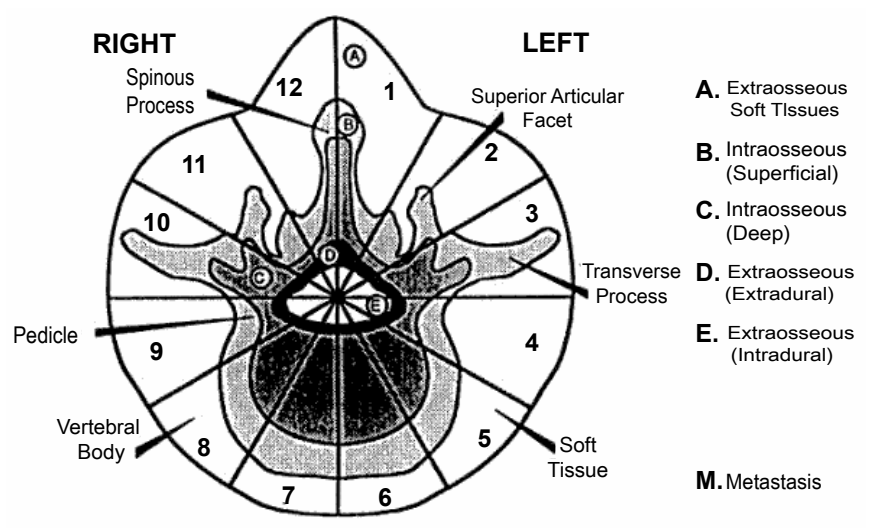

Figure 1: WBB surgical staging system,1997 [9].

*Corresponding author: Alexandros Zachos, orthopaedic Department, University of Sassari, Italy; E-mail: zalexandros@libero.it

Received December 12, 2011; Accepted January 18, 2012; Published January 21,2012

Citation: Zachos A, Leali PT, Doria C (2012) Percutaneous Treatment of the Spinal Metastases. J Spine 1:110. doi:10.4172/2165-7939.1000110

Copyright: ( 2012 Zachos A, et al. This is an open-access article distributed under the terms of the Creative Commons Attribution License, which permits unrestricted use, distribution, and reproduction in any medium, provided the original author and source are credited. 
therapy is first-line for most patients who present spinal metastasis may be used as adjunct for residual radiographic tumor. Also the therapy with bisphosphonates has a big importance. Bisphosphonates are potent inhibitors of the osteoclastic bone resorption that is associated with skeletal metastases. If the patient cannot be subjected to surgery, an external contention can help him for the pain relief.

Surgical treatment of the spinal metastases: It's very important the surgical staging and the preoperative prognostic score in order to choose the best surgical treatment. There are many surgical staging system like [9, figure 1,10] (Table 1).

Also, it's well known the existence of two types of surgery, the "open surgery" and "percutaneous" surgery. Both types of surgery may be useful in the treatment of the vertebral metastasis. Recent advancements in surgical techniques allow a less aggressive approach (percutaneous surgery) of the patient with better results in terms of decreasing pain, improvement of the quality of life.

\section{Materials and Methods}

We opted for the percutaneous treatment; the reasons were the high age, comorbidities (Table 2), multiple metastases in bone and visceral sites. The surgical techniques that we used were a) coablation (Figures 2a,2b) associated with vertebroplasty (Figures 3a,3b) and b) Percutaneous osteosynthesis (Figures 4-6). In our clinic, in the last 5 years (August 2006 to October 2011), were treated 115 patients; 56 males and 59 females (Table 3), aged between 42 and 88 years (mean 65 years). With vertebroplasty and ablation (Figures 2,3) 76 patients (66.08\%), (94 vertebrae). We used the Percutaneous osteosynthesis (Figures 4-6) in 39 patients (33.92\%).

In both types of percutaneous surgery are very important the operating room set up and the surgical technique:

\section{Operating room set up and surgical technique}

The patient undergoes general anesthesia. Is positioned, then, lying prone on the bed radiolucent. With a wire kirschner and the help of the image intensifier will highlight the vertebrae to be treated is drawn on the skin, above the vertebrae, the endplates with their peduncles. Appropriate image of the vertebra should show the upper and lower vertebral limiting double profile with no visible. The pedicles should appear just below the limiting upper and spinous process should be centered between the two pedicles. In latero-lateral view constraining the top should look not split and the two pedicles should be completely overlapped, and the back wall of the vertebral body in a perfect LL view should not show double contour. After careful sterilization of the operating field, we proceed with the insertion of the trocar inside the right peduncle of the affected level. The fascia is incised and opened Advances until arrive at the midline in the anteroposterior projection and to the anterior third in lateral projection. Once we are sure of arriving at the right place, a guide wire is inserted into the cannulated trocar. With it you get to touch the front wall of the vertebral body. Then it depends on the surgical technique that you want. In the case of percutaneous osteosynthesis (Figures 4-6), we proceed with the milling and cannulated screw insertion. In the case of coablation (Figure 2a,2b) and vertebroplasty (Figure 2c,2d), (Figure 3) insert the instruments suitable to perform coablation and subsequently vertebroplasty.

Coablation and vertebroplasty: It's a minimally invasive percutaneous procedure determines destruction of the lesion (with the help of the heat) and subsequent stability of the vertebra. Necrotizing tumor tissue by heat ablation optimizes cement distribution, facilitated by changes in tumor consistency as a result of thermal alterations [11]. Very useful for the patients affected by serious diseases where open surgery cannot be applied (Table 2). The "difficult patients" can be subjected to surgery because we have reduced surgical times, local anesthesia, limited blood loss. Furthermore, the absence of intra and postoperative complications and reduced costs of hospitalization are other factors. The correct surgical indications are the small painful lesions with pathologic fracture risk, lesions that involved the vertebral body [(intra-compartmental) type 1, max type 2 according to Tomita's classification]. Other indications are the failure of radiation therapy, secondary deformities of the spine and the intractable pain unresponsive to chemo-radio-hormone therapy also unstable compression fracture that demonstrates movement at the wedge deformity. Certainly, percutaneous vertebroplasty (Figure 3) after coablation (Figures $2 \mathrm{a}, 2 \mathrm{~b})$ stabilizes the vertebrae and provides immediate pain relief. It has been postulated that the analgesia provided by vertebroplasty may derive from stabilization of microfractures, reduction of mechanical forces, and/or destruction of the nerve terminals by the cytotoxicity of PMMA in the cement due to vascular, chemical, and thermal forces [12-15]. The contraindications of the combined procedure consist of osteoblastic tumors, fractures with retropulsion of the fragments within neural foramen, spread of tumor within the epidural space, local infection (osteomyelitis, discitis or epidural abscess), coagulative disorders, pain not related to vertebral collapse, steady asymptomatic fractures, and tumor involvement or missing integrity of pedicles or joint facets [16-19].

Percutaneous osteosynthesis: The percutaneous osteosynthesis (Figures 4-6) is an alternative for the stabilization of the vertebral metastatic lesions in which it is expected a good response to a future

\begin{tabular}{|c|c|c|c|c|c|c|}
\hline \multicolumn{4}{|c|}{ Scoring System } & \multirow[b]{2}{*}{ Prognostic Score } & \multirow[b]{2}{*}{ Treatment Goal } & \multirow[b]{2}{*}{ Surgical Strategy } \\
\hline \multirow{2}{*}{ Point } & \multicolumn{3}{|c|}{ Prognostic Factors } & & & \\
\hline & Primary Tumor & Visceral mets. ${ }^{*}$ & Bone mets ** & 2 & \multirow{2}{*}{ Long-term local control } & \multirow{2}{*}{ Wide or marginal Excision } \\
\hline & & & & & & \\
\hline \multirow[t]{2}{*}{1} & \multirow{2}{*}{$\begin{array}{c}\text { Slow Groth (breast, thyroid, } \\
\text { etc.) }\end{array}$} & & \multirow{2}{*}{$\begin{array}{l}\text { Solitary or } \\
\text { isolated }\end{array}$} & 4 & \multirow{2}{*}{ Middle term local control } & \multirow{2}{*}{$\begin{array}{l}\text { Marginal or Intralesional } \\
\text { excision }\end{array}$} \\
\hline & & & & 5 & & \\
\hline \multirow[t]{2}{*}{2} & \multirow[t]{2}{*}{$\begin{array}{l}\text { Moderate Growth (Kidney, } \\
\text { Uterus, etc.) }\end{array}$} & Treatable & \multirow[t]{5}{*}{ Multiple } & 6 & \multirow{2}{*}{ Short term palliation } & \multirow{2}{*}{ Palliative surgery } \\
\hline & & \multirow{4}{*}{ Untreatable } & & 7 & & \\
\hline \multirow{3}{*}{4} & \multirow{3}{*}{$\begin{array}{l}\text { Rapid Growth (Lung, } \\
\text { Stomach etc.) }\end{array}$} & & & 8 & \multirow{3}{*}{ Terminal Care } & \multirow{3}{*}{ Supportive care } \\
\hline & & & & 9 & & \\
\hline & & & & 10 & & \\
\hline
\end{tabular}

${ }^{*}$ No visceral mets. $=0$ point ${ }^{* *}$ Bone mets. Including spinal mets

Table 1. Tomita preoperative prognostic score [10]. 
chemotherapy or radiotherapy. The decision for surgery was made after discussion with the oncological team in all cases. We have considered such as correct surgical indications the vertebral lesions with high risk of pathologic fracture, the correction of kyphotic or scoliotic curves secondary to pathological vertebral collapse. Also all lesions protruding from the vertebral body in any direction, so the spinal osteosynthesis acts like an internal fixation. Allow the patient to prevent bedsores required for long periods of time. Many times we associate the percutaneous osteosynthesis (Figures 4-6) with a mini decompressive laminectomy in order to give better pain control and allow patient's mobilization. To emphasize the use of coablation (Figures 2a,2b) and vertebroplasty with the transpeduncolar osteosynthesis in cases that we
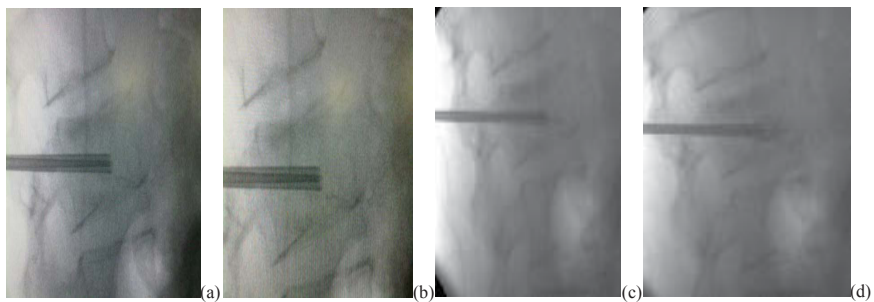

Figure 2: Intraoperative radiographs, $(a, b)$ : Insertion of the trocar and subsequent coablation. It highlights the clear halo that is formed inside the vertebral body. $(\mathrm{c}, \mathrm{d})$ : Insertion of the cement after coablation.
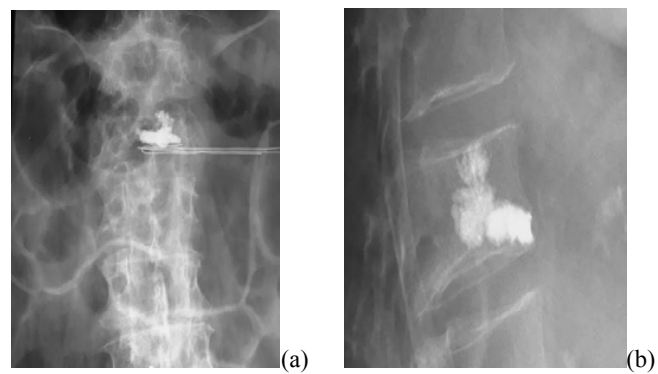

Figure 3: $(a, b)$ : Final result in ap and lateral radiographs.
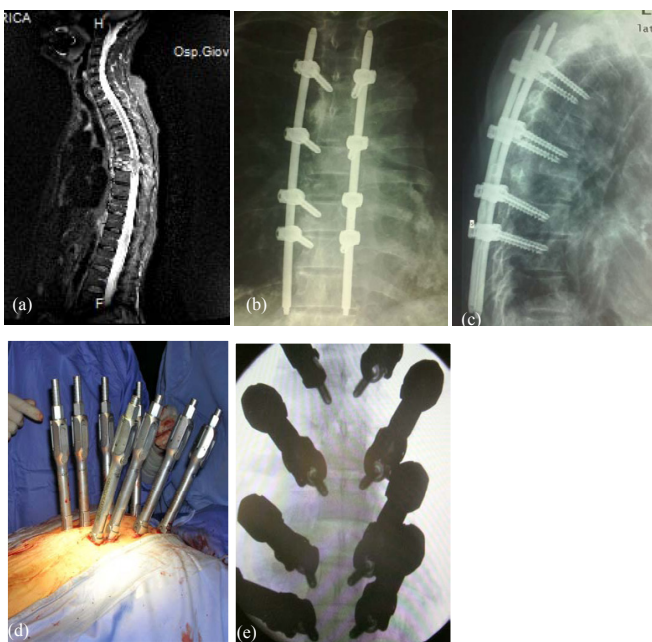

Figure 4: 63 years old female patient suffering from colon cancer. After 4 years shows a strong back pain. (a): MRI showing a metastasis to the sixth thoracic vertebra. $(b, c)$ : Percutaneous transpedicular osteosynthesis from third to eighth thoracic vertebra, final radiographs in anteroposterior and lateral projections. $(\mathrm{d}, \mathrm{e})$ : Intraoperative images.

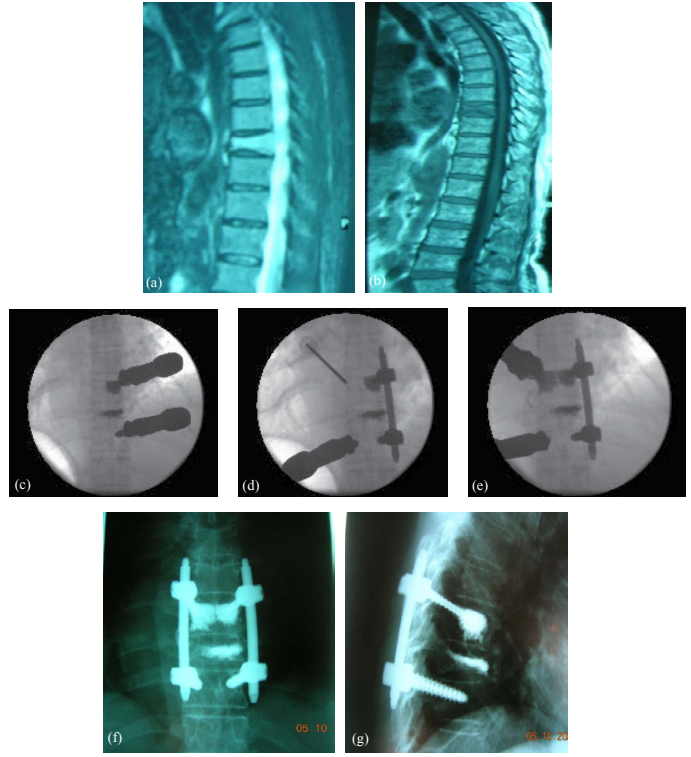

Figure 5: $(a, b): 74$ years old male patient, suffering from prostate cancer. Metastasis to the sixth thoracic vertebra. (c,d,e): Intraoperative images of percutaneous stabilization. Also note the vertebroplasty of the sixth dorsal vertebra, which had previously been submitted in coablation. $(\mathrm{f}, \mathrm{g})$ : anteroposterior and lateral radiographs.

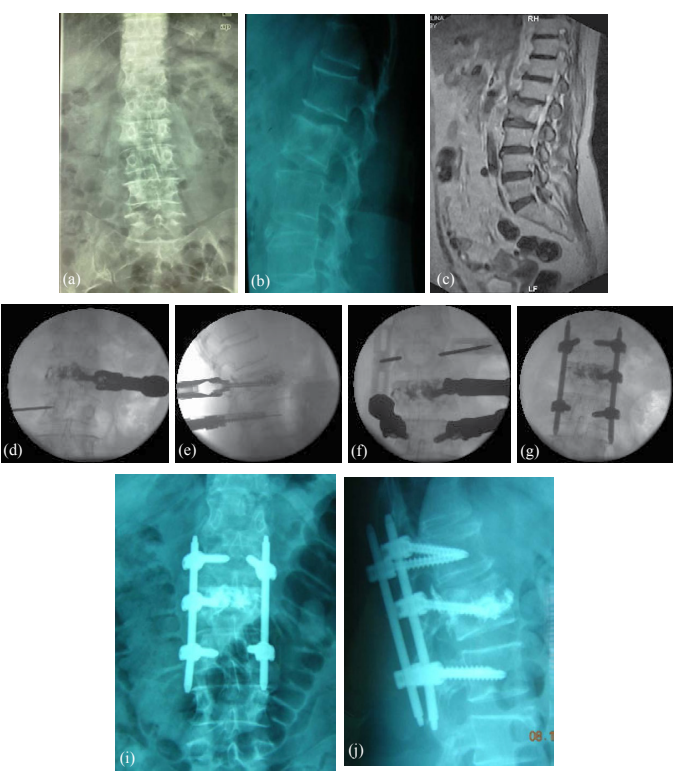

Figure 6: (a,b,c) Female patient 54 years old, affected by breast cancer. Radiographs and MRI where we can observe the involvement of the second lumbar vertebra. ( $\mathrm{d}, \mathrm{e}, \mathrm{f}, \mathrm{g}$ ): Intraoperative images of percutaneous stabilization. Also note the vertebroplasty of the second lumbar vertebra, which had previously been submitted in coablation. $(\mathrm{i}, \mathrm{j})$ : anteroposterior and lateral radiographs

considered appropriate like the small painful lesions with pathologic fracture risk, lesions that involved the vertebral body.

\section{Results}

In both types of treatment, the postoperative elapsed were regular with early mobilization and regression of pain. The median duration of the operation of the patients who treated with coablation (Figures $2 \mathrm{a}, 2 \mathrm{~b}$ ) and vertebroplasty (Figures $3 \mathrm{a}, 3 \mathrm{~b}$ ) was 30 minutes and the median blood loss was 15 milliliters. Postoperatively, all patients were 


\begin{tabular}{|l|l|}
\hline Comorbidities & Number Patients \\
\hline Chronic heart failure & 7 \\
\hline Diabetes (type I and II) & 29 \\
\hline Systemic Lupus Eritematosus & 1 \\
\hline Rheumatoid Arthritis & 2 \\
\hline Hypertension & 89 \\
\hline Stroke & 6 \\
\hline Mediterranean Anemia & 8 \\
\hline Hypothyroidism & 5 \\
\hline H. I. V & 2 \\
\hline Chronic hepatitis & 12 \\
\hline Crohn's disease & 1 \\
\hline Chronic renal failure & 7 \\
\hline Chronic obstructive pulmonary disease & 11 \\
\hline
\end{tabular}

Table 2: Comorbidities of the patients who were treated with percutaneous mode.

\begin{tabular}{|l|l|l|}
\hline Primary Cancer & Males & Females \\
\hline Breast & 0 & 18 \\
\hline Colon & 11 & 8 \\
\hline Kidney and Renal pelvis & 4 & 2 \\
\hline Lung and Bronchus & 14 & 9 \\
\hline Liver & 11 & 7 \\
\hline Urinary Bladder & 3 & 5 \\
\hline Thyroid & 1 & 4 \\
\hline Prostate & 12 & 0 \\
\hline Endometrium (Uterus) & 0 & 6 \\
\hline
\end{tabular}

Table 3: The primary sites of cancer and the incidence to both sexes.

allowed to walk without the use of braces. The median duration of hospitalization was two days. Most of the patients were discharged to an oncology unit for additional treatment and rehabilitation. There were no perioperative or immediate postoperative deaths. Forty one patients (35.65\%) had at least one reoperation: Twenty nine (25.21\%) because of progression of the primary disease. Twelve patients (10.43\%) had epidural compression at a spinal level. In the patients who treated with percutaneous osteosynthesis (Figures 4-6), the median duration of the operation was 74 minutes and the median blood loss was 108 milliliters. The median duration of hospitalization was seven days. Most of the patients were discharged to an oncology unit for additional treatment and rehabilitation. No patients were admitted to the intensive care unit. There were no perioperative or immediate postoperative deaths.

\section{Conclusion}

The diagnosis and treatment of spinal metastases require multidisciplinary review. The optimal treatment depends from a balance between the morbidity of the surgical procedure, the estimated survival time, and the overall quality of life. We believe that these minimally invasive techniques are certainly a viable alternative to "open" traditional spine surgery and can help in order to reduce the pain and to restore the stability. The benefits of "minimal invasive" surgery are reduced muscular trauma, smaller wound and by that less risk of wound complications, less bleeding and faster recovery which for this patient category could mean a longer time with improvement in quality of life compared to open surgery. Symptomatic patients deemed poor operative candidates for open surgery due to age, comorbidities (Table 2), metastatic burden or limited life expectancy may benefit from a percutaneous mini-invasive surgery. Minimally invasive techniques with quick pain relief can be an alternative option to conventional treatments [20].

\section{References}

1. Bach F, Larsen BH, Rohde K, Børgesen SE, Gjerris F, et al. (1990) Metastatic spinal cord compression. Occurrence, symptoms, clinical presentations and prognosis in 398 patients with spinal cord compression. Acta Neurochir (Wien) 107: 37-43.

2. Perrin RG (1992) Metastatic tumors of the axial spine. Curr Opin Oncol 4: 525532.

3. Byrne TN (1992) Spinal cord compression from epidural metastases. N Engl J Med 327: 614-619.

4. Gerszten PC, Welch WC (2000) Current surgical management of metastatic spinal disease. Oncology (Williston Park) 14: 1013-1024.

5. Gilbert RW, Kim JH, Posner JB (1978) Epidural spinal cord compression from metastatic tumor: diagnosis and treatment. Ann Neurol 3: 40-51.

6. Taneichi H, Kaneda K, Takeda N, Abumi K, Satoh S (1997) Risk factors and probability of vertebral body collapse in metastases of the thoracic and lumbar spine. Spine (Phila Pa 1976) 22: 239-245.

7. Harrington KD (1986) Metastatic disease of the spine. J Bone Joint Surg Am 68: 1110-1115.

8. Perrin RG, Laxton AW (2004) Metastatic spine disease: epidemiology, pathophysiology, and evaluation of patients. Neurosurg Clin N Am 15: 365-373.

9. Boriani S, Weinstein JN, Biagini R (1997) Primary bone tumors of the spine Terminology and surgical staging. Spine (Phila Pa 1976) 22: 1036-1044.

10. Tomita K, Kawahara N, Kobayashi T, Yoshida A, Murakami H, et al. (2001) Surgical strategy for spinal metastases. Spine (Phila Pa 1976) 26: 298-306.

11. Schaefer O, Lohrmann C, Markmiller M, Uhrmeister P, Langer M (2003) Technical innovation. Combined treatment of a spinal metastasis with radiofrequency heat ablation and vertebroplasty. AJR Am J Roentgenol 180: 1075-1077.

12. Weill A, Chiras J, Simon JM, Rose M, Sola-Martinez T, et al. (1996) Spinal metastases: indications for and results of percutaneous injection of acrylic surgical cement. Radiology 199: 241-247.

13. Mathis JM, Barr JD, Belkoff SM, Barr MS, Jensen ME, et al. (2001) Percutaneous vertebroplasty: a developing standard of care for vertebral compression fractures. AJNR Am J Neuroradiol 22: 373-381.

14. Cotten A, Dewatre F, Cortet B, Assaker R, Leblond D, et al. (1996) Percutaneous vertebroplasty for osteolytic metastases and myeloma: effects of the percentage of lesion filling and the leakage of methyl methacrylate at clinical follow-up. Radiology 200: 525-530.

15. Radin EL, Rubin CT, Thrasher EL, Lanyon LE, Crugnola AM, et al. (1982) Changes in the bone-cement interface after total hip replacement. An in vivo animal study. J Bone Joint Surg Am 64: 1188-1200.

16. Fourney DR, Schomer DF, Nader R, Chlan-Fourney J, Suki D, et al. (2003) Percutaneous vertebroplasty and kyphoplasty for painful vertebral body fractures in cancer patients. J Neurosurg 98: 21-30.

17. Linville DA 2nd (2002) Vertebroplasty and kyphoplasty. South Med J 95: 583 587.

18. Ledlie JT, Renfro M (2003) Balloon kyphoplasty: one-year outcomes in vertebral body height restoration, chronic pain, and activity levels. J Neurosurg 98: 36-42.

19. Masala S, Fiori R, Massari F, Simonetti G (2003) Vertebroplasty and kyphoplasty: new equipment for malignant vertebral fractures treatment. J Exp Clin Cancer Res 22: 75-79.

20. Gangi A, Guth S, Imbert JP, Marin H, Jeung MY, et al. (2003) Radiofrequency ablation of bone metastases. ECR Cum Laude. 